\title{
The Structure and Stability of Subjective Well-Being: a Structure Equation Modelling Analysis
}

\author{
Iolanda C. Costa Galinha • José Luís Pais-Ribeiro
}

Received: 10 April 2009 / Accepted: 16 April 2009 /

Published online: 5 May 2009

(C) Springer Science + Business Media B.V./

The International Society for Quality-of-Life Studies (ISQOLS) 2009

\begin{abstract}
The purpose of the study is to test the structure and the stability of Subjective Well-Being (SWB), measured through cognitive and affective self-report measures, in global and specific levels of analysis. A sample of 303 adult students was collected and replicated in a 2 month interval. The best model of SWB shows an intercorrelated fourfactor structure - Satisfaction with Life, Negative Affect, Positive Affect and Global Subjective Well-being. Results suggest that Global Happiness and Global Satisfaction are measuring the same aspect of SWB. All measures of SWB, in study, show good construct validity and reliability in a 2 month replication. Positive and Negative Affect are significantly weakly correlated. Positive Affect is the most stable variable of SWB, in a short-term interval. Researchers must be aware of the issues related to the measurement of SWB as the order of the items in a questionnaire and the implications of using global or specific measures, cognitive or affective dimensions of the concept, that represent different aspects of the concept. Further study is needed to analyse the structure of SWB with different measures and the relationship between its components.
\end{abstract}

Keywords Subjective well-being structure $\cdot$ Stability $\cdot$ Satisfaction with life $\cdot$ Positive affect $\cdot$ Negative affect $\cdot$ Structure equation modelling

\section{The Structure and Stability of Subjective Well-Being: Happiness, Satisfaction with Life, Positive Affect and Negative Affect}

Subjective well-being has been classified as a diffuse concept and despite the recent systematic study, several authors alert for the need of integration and delimitation of

I. C. C. Galinha ( $\square)$

Department of Psychology of Universidade Autónoma de Lisboa, Rua Cruz de Santa Apolónia, 64, $3^{\circ} \mathrm{Dt}^{\circ}, 1100-188$ Lisboa, Portugal e-mail: iolandag@yahoo.com 